\title{
Eksistensi Nilai Sosial Budaya Ndeu Paki Oi Mbaru Pada Masyarakat Donggo Kabupaten Bima
}

\author{
Sumitro ${ }^{1}$, Shermina Oruh $^{2}$, Andi Agustang ${ }^{3}$ \\ ${ }^{1}$ Mahasiswa Pascasarjana S3 Sosiologi Universitas Negeri Makassar \\ ${ }^{2}$ Dosen Universitas Pejuang Republik Indonesia \\ ${ }^{3}$ Dosen Universitas Negeri Makassar \\ Email: sumitro765@gmail.com, shoruh68@gmail.com, andiagust63@gmail.com
}

\begin{abstract}
This study aims to determine the existence of the social value of the ndeu paki oi mbaru community of donggo, bima regency. this research is a qualitative descriptive research that aims to explain a situation or reality carefully and in accordance with the circumstances in society. the subjects in this research can be selected by purposive sampling, namely by determining the informants who have competence and know a problem to be studied. the number of informants in this study were 20 people. the informants who were targeted in this study were community members who were married, those who were not married, and those who were about to get married. an urgent problem in this research is the fading identity of the paki oi mbaru ceremony, currently in the donggo traditional wedding ceremony, the donggo community has rarely carried out the ceremony before the marriage contract. from this phenomenon, researchers will study the existence of the paki oi mbaru ceremony in the donggo community, bima regency. The results showed that the paki oi mbaru ceremony was rarely practiced by the donggo community, bima regency. the causes of the disappearance of the ndeu paki oi mbaru ceremony in the donggo community are as follows; 1 . the internal factor of the community itself because it does not attach importance to tradition and culture from generation to generation and there is an assumption that when carrying out traditions it only costs a lot of money and wastes a lot of time. 2. external factors, namely contact with other cultures, such as cultural acculturation, the influence of mass media and modernization. The conclusion of this study is that the ndeu paki oi mbaru ceremony is no longer carried out by the donggo community in general, except that only certain people still carry it out and even then only a few of the existing donggo community.
\end{abstract}

Keywords: Existence, socio-cultural values, ndeu paki oi mbaru.

\begin{abstract}
Abstrak
Penelitian ini bertujuan untuk mengetahui eksistensi nilai sosial ndeu paki oi mbaru masyarakat Donggo Kabupaten Bima. Penelitian ini merupakan penelitian yang bersifat deskriptif kualitatif yang bertujuan menjelaskan suatu keadaan atau realitas secara teliti dan sesuai dengan keaadan pada masyarakat. Adapun Subjek pada penelitian penelitian ini dapat dipilih secara purposive sampling, yakni dengan cara penentuan informan yang memiliki kompetensi serta mengetahui suatu masalah yang akan diteliti. Adapun jumlah informan dalam penelitian ini sebanyak 20 orang. informan yang menjadi sasaran dalam penelitian ini yaitu anggota masyarakat yang sudah melangsungkan pernikahan, yang belum menikah, dan yang akan menikah. Masalah yang urgen dalam penelitian ini yaitu semakin pudarnya identitas upacara paki oi mbaru, saat ini di dalam upacara perknikahan adat donggo masyarakat sudah jarang dilaksnanakan oleh masyarakat donggo sebelum melangsungkan akad nikah . dari fenomena tersebut peneliti akan mengakaji tentang eksistensi upacara paki oi mbaru pada masyarakat donggo kabupaten bima. Hasil penelitian menunjukkan bahwa, upacara paki oi mbaru sudah jarang dipraktekkan oleh masyarakat donggo kabupaten bima. Penyebab mulai hilangnya upacara ndeu paki oi mbaru pada masyarakat donggo adalah sebagai berikut; 1.faktor internal masyarakat itu sendiri karena sudah tidak mementingkan tradisi dan budaya secara turun temurun serta ada anggapan bahwa ketika melakukan tradisi justeru hanya mengabiskan banyak biaya dan banyak membuang waktu. 2.faktor dari eksternal yaitu adanya kontak dengan kebudayaan lain, seperti adanya akulturasi budaya, pengaruh media massa dan modernisasi. Kesimpulan penelitian ini adalah upacara ndeu paki oi mbaru sudah tidak dilakukan oleh masyarakat donggo pada umummnya, kecuali hanya orang-orang tertentu saja yang masih melaksanakannya dan itupun hanya sedikit saja dari masyarakat donggo yang ada.
\end{abstract}

Kata Kunci : Eksistensi, nilai sosial budaya, ndeu paki oi mbaru.

\section{PENDAHULUAN}

Indonesia adalah yang banyak memiliki suku bangsa, adat istiadat yang tersebar di seluruh wilayah kesatuan Indonesia. Wilayah Indonesia mulai dari sabang sampai merauke.
Setiap suku bangsa Indonesia memiliki adat istiadat serta kebuadayaan yang berbeda-beda diatara satu dengan yang lainnya. Setiap masyarakat dan kebudayaan yang ada tidak bisa dipisahkan antara satu dengan yang 
lainnya, sebab dimana ada masyarakat disitu ada kebudayaan.

Di dalam suatu kebudayaan setiap masyarakat memiliki ciri khasnya masingmasing yang tidak bisa disatukan dengan yang lainnya, tetapi harus diterima menjadi sebuah keniscayaan dalam keragaman budaya yang ada. Kebudayaan dalam masyarakat Indonesia yang berbeda antara suku yang satu dengan suku yang lainnya, bukan berarti tidak sama dalam unsur-unsur kebudayaan yang universal. Adapun unsur-unsur budaya secara umum adalah sebagai berikut; 1.bahasa, 2.sistem pengetahuan,3.organisasi sosial, 4. sistem peralatan hidup dan tehnologi, 5. sistem mata pencaharian hidup, 6.sistem religi, 7. kesenian. (Koentjaran ingrat, 2009:165).

Masyarakat adalah satu kesatuan manusia yang hidup dan berinteraksi berdasarkan pada sistem adat istiadat tertentu yang bersifat secara terus menerus dan terikat oleh suatu identitas bersama. (Koentjaraningrat, 2009:118). Hal yang sama pada masyarakat donggo, merupakan kumpulan manusia donggo yang selalu berinteraksi berdasarkan adat istiadatnya dan bersifat terus menerus serta terikat oleh suatu kesamaan identitas.

Ilmuan sosiologi sudah melakukan klasifikasi terhadap masyarakat yang statis dan dinamis. Suatu Masyarakat dikatakan statis ketika masyarakatnya sangat sedikit mengalami perubahan serta kecenderungannya lambat dalam perubahan sosial. Sedangakan pada masyarakat yang dinamis merupakan masyarakat dengan kecenderungan selalu mengalami kondisi perubahan yang cepat atau revolusi. Suatu perubahan bukanlah berarti semata-mata kearah kemajuan (progress) saja, namun juga dapat berarti kemunduran dari bidang-bidang kehidupan tertentu.

Berkaitan dengan uraian diatas bahwa yang menjadi kajian atau fenomena yang berkembang dewasa ini adalah soal eksistensi transformasi dan relasi agama dengan budaya lokal. Pada Setiap suku atau etnisyang ada memiliki budaya yang berbeda antara yang satu dengan yang lainnya. Karena pada setiap budaya pasti mempunyai ciri khasnya atau disebut local culture. Hal yang sama juga bagi masyarakat etnis bima yang memiliki budaya khas serta tetap mempertahankan dan menjunjung tinggi nilai-nilai luhur dari kebudayaan yang ada.

Pada praktek kehidupan masyarakat bima cenderung bersifat seremonial, selalu ingin meresmikan suatu kegiatan atau hajatan melalui upacara. Upacara merupakan tindakan atau perilaku yang terikat pada nilai dan norma tertentu yang didasarkan pada adat atau kepercayaan. Nilai dapat dilihat sebagai pedoman atau petunjuk dalam bertindak sekaligus sebagai tujuan kehidupan manusia itu sendiri (Basrowi, 2005:80). Tradisi-tradisi upacara yang dilakukan oleh masyarakat bima berkaitan erat dengan cara kehidupan manusia. Kegiatan tersebut dilaksanakan dalam rangka menunaikan suatu keadaan untuk mencapai tujuan tertentu. Bagi masyarakat bima ritual ini merupakan adat istiadat yang sakral. Sehingga pada pelaksanaan upacara tersebut sangat dibutuhkan kesiapan yang benar-benar matang.

Pada masyarakat donggo ada salah satu acara adat yang dilakukan oleh masyarakat yang akan melangsungkan pernikahan adalah tradisi ndeu paki oi mbaru, kegiatan ritual ini dilakukan sebelum dilaksanakan akad nikah, dengan tujuan untuk membersihkan jiwa dan calon pengantin yang akan melangsungkan pernikahan. Sehingga calon mempelai menjadi bersih pikiran dan hatinya serta yang tidak kalah pentinyanya adalah bersih secara spiritual. Pada upacara ndeu paki oi mbaru ini memiliki tata cara atau urutan serta perlengkapan (soji) yang sesuai aturannya. Nilai-nilai yang terkandung di setiap tahapan alur pelaksanaan dan perlengkapannya semua menjadi penting untuk dilakukan karena mempunyai arti dan makna.

Pada pernikahan masyarakat donggo ada tradisi yang dilakukan sebelum proses pernikahan, ada kebiasaan yang sudah terjadi secara turun temurun pada adat donggo adalah diawali dengan upacara Ndeu paki oi mbaru yang biasa dilaksanakan sebagai proses penyucian jiwa dan raga yang dilaksanakan sehari sebelum ijab kabul. Sehingga hubungan cinta kasih antara kedua mempelai, setelah melalui proses dan pertimbangan yang matang, 
yang pada akhirnya disahkan melalui perkawinan, serta dapat menjalin hidup bersama secara resmi selaku suami istri baik dari hukum negara, adat dan agama. (Sumarsono. 2007: 21).

Kata ndeu paki oi mbaru berarti mandi. Ndeu paki oi mbaru mengandung arti memandikan calon pengantin dengan niat membersihkan diri agar menjadi bersih dan murni/suci lahir batin. Bersih lahir dan batin yang dimaksud adalah ketika calon pengantin sudah menikah tidak lagi terganggu dengan roh-roh jahat yang menguasai manusia.

Pada pelaksanaan tradisi ndeu paki oi mbaru ada orang khusus yang bertugas untuk memandikan calon pengantin tersebut adalah sando (orang yang memiliki pengetahuan tentang adat istiadat pada masyarakat tersebut). Ndeu paki oi mbaru ini akan diakhiri oleh sando (orang yang dituakan) dengan memecah kendi/klenthing dari tanah liat.

Adapun hakikat pada prosesi mandi ndeu paki oi mbaru dalam upacara pengantin adat donggo bukan sekedar membersihkan badan tetapi yang terpenting juga adalah membersihkan jiwa. Membersihkan diri dari sifat-sifat yang kurang baik serta dari segala gangguan dan halangan sehingga disaat prosesi ijab qabul tidak ada lagi hal-hal yang mengganggu. Sehingga yang diharapkan pengantin dapat menjalani hidup dengan bersih dan suci.

Pada masyarakat donggo upacara ndeu paki oi mbaru sudah jarang kita jumpai pada kehidupan masyarakat. Realitas ini yang membuat penulis gelisah, sehingga peneliti ingin mengetahui pandangan masyarakat terhadap upacara ndeu paki oi mbaru serta keberadaan upacara tersebut pada masyarakat donggo kabupaten bima.

Berdasarkan latar belakang sudah diuraikan di atas peneliti tertarik untuk melakukan penelitian dengan dengan judul "Eksistensi nilai sosial budaya ndeu paki oi mbaru masyarakat donggo kabupaten bima".

\section{METODE PENELITIAN}

Metode yang digunakan dalam penelitian ini adalah deskriptif kualitatif dengan pendekatan studi kasus. Deskripstif kualitatif suatu cara atau strategi yang dipilih oleh penulis untuk mengamati suatu fenomena yang terjadi, mengumpulkan informasi serta akan menyajikan hasil penelitian.

Menurut Moleong (2014: 6) bahwa penelitian kualitatif adalah penelitian dengan maksud untuk memahami fenomena yang dialami oleh subjek penelitian misalnya persepsi, perilaku, motivasi, tindakan secara holistik dengan cara deskriptif dalam bentuk argumentasi dan narasi pada suatu konteks, khususnya yang alamiah dengan memanfaatkkan berbagai metode alamiah.

Hal yang sama juga disampaikan oleh David Williams (1995) (dalam Moleong 2014: 5) menyatakan bahwa: "penelitian kualitatif pengumpulan data pada suatu latar alamiah, dengan menggunakan metode alamiah, dan dilakukan oleh orang atau peneliti yang tertarik secara alamiah".

Pada penelitian ini penulis menggunakan penelitian kualitatif deskriptif. Penelitian deskriptif ini bertujuan untuk mengumpulkan data dan informasi aktul secara rinci yang mengambarkan gejala yang ada, serta melakukan identifikasi masalah atau memeriksa kondisi dan praktik-praktik yang berlaku.

Metode deskriptif digunakan untuk menggambarkan secara sistematis berbagai macam fenomena atau fakta pada bidang tertentu. Jadi kualitatif deskriptif merupakan penelitian untuk membuat deskriptif, gambaran atau sistematis, faktual dan akurat mengenai sifat-sifat situasi, kondisi atau fenomena dengan menggunakan data berupa kata-kata tertulis atau lisan dari orang-orang dan objek yang diamati secara utuh.

\section{A. Lokasi dan Subjek Penelitian}

Adapun lokasi Penelitian ini dilaksanakan di kecamatan Donggo Kabupaten bima, subjek penelitian ini adalah masyarakat suku bima yang bertempat tinggal diwilayah kecamatan donggo Kabupaten bima yaitu tokoh masyarakat, tokoh adat, sesepuh desa untuk mewakili kaum tua dan pasangan suami istri yang sudah menikah, atau merencanakan pernikahan serta yang belum menikah mewakili dari generasi mudah, yang dianggap mengetahui informasi dan masalah secara 
mendalam mengenai upacara ndeu paki oi mbaru.

\section{B. Informan}

Adapun Informan dalam penelitian ini adalah para tokoh masyarakat, tokoh adat, tokoh agama, tokoh pemuda serta pasangan suami isteri yang sudah menikah, pasangan calon pengantin yang akan menikah. Selain itu informan juga harus yang sudah lama atau mengetahui informasi serta masalahnya secara mendalam untuk menjadi sumber data yang valid sehingga kemungkinan pilihan informan dapat berkembang sesuai dengan kebutuhan dan kemantapan peneliti memperoleh data (Sutopo, 2002:56). Dengan harapan dari informan yang dipilih akan memberikan informasi yang mendalam terkait tentang prosesi upacara ndeu paki oi mbaru secara komprehensif.

\section{E. Instrument Penelitian}

Sugiyono (2013:59) mengatakan bahwa yang menjadi instrument dalam penelitian kualitatif adalah peneliti itu sendiri. Oleh sebab itu peneliti sebagai instrument perlu pemahaman tentang metode penelitian kualitatif secara baik, penguasaan terhadap bidang yang akan diteliti, kesiapan dan bekal dan finansial disaat di lapangan, dan mengevaluasi diri.

Instrument penelitian yang sederhana dapat digunakan dalam penelitian ini, yaitu pedoman wawancara. Pedoman wawancara ini diharapkan bisa membantu peneliti dalam melengkapi data dan membandingkan data yang diperoleh.

\section{F. Teknik Pengumpulan Data}

Adapun teknik pengumpulan data dalam penelitian ini anatara lain:

1. Observasi

Observasi yaitu suatu cara atau teknik dengan terjun langsung ke lokasi penelitian, melakukan pengamatan secara langsung terhadap objek yang akan diteliti. Adapun objek penelitian ini dilakukan di kecamatan donggo kabupaten bima.

2. Wawancara

Wawancara adalah suatu kegiatan interaksi atau percakapan langsung dengan informan penelitian percakapan tersebut dilakukan oleh dua pihak, yaitu pewawancara yang mengajukan pertanyaan dan informan yang memberikan jawaban atas pertanyaan tersebut (Moleong 2014:186). Metode ini sangat membantu bagi peneliti untuk menyampaikan beberapa pertanyaa lisan secara langsung kepada informan dengan tetap mengacu pada panduan atau pedoman wawancara yang telah disiapkan oleh peneliti.

3. Dokumentasi

Berdasarkan Kamus Besar Bahasa Indonesia istilah dokumentasi dapat diartikan sebagai sesuatu yang tertulis, terekam atau tercatat yang dapat dipakai sebagai bukti atau keterangan. Dokumentasi juga dapat berupa pengumpulan-pengumpulan data berupa gambar-gambar atau foto-foto, yang hasilnya dapat dijadikan sebagai bahan lampiran maupun data tambahan yang dibutuhkan di dalam penelitian.

\section{G. Teknik Analisis Data}

Adapun Teknik analisa yang digunakan dalam penelitian ini adalah dengan teknik analisa kualitatif yang memuat memuat tahapan-tahapan sebagai berikut; interaktif kegiatan analisis data yang dimulai dari data reduction, data display, dan conclusion drawing/verification".

\section{HASIL DAN PEMBAHASAN \\ Eksistensi Nilai Sosial Budaya Ndeu Paki Oi Mbaru Masyarakat Donggo Kabupaten Bima.}

Pada masyarakat donggo Upacara ndeu paki oi mbaru merupakan salah satu dari sekian banyak tata urutan pernikahan adat donggo, namun apakah semua masyarakat donggo memahami berbagai macam hal tentang upacara ndeu paki oi mbaru? diantaranya tentang maksud dan tujuan upacara ndeu paki oi mbaru, nilai sosial budaya yang ada di dalamnya serta prosesi pelaksanan upacara ndeu paki oi mbaru itu sendiri. Untuk mengetahui berbagai macam informasi tentang upacara ndeu paki oi mbaru pada masyarakata donggo. Maka peneliti akan menguraikannya berdasarkan data yang 
diperoleh di lapangan antara lain sebagai berikut;

1. Pandangan masyarakat tentang eksistensi nilai sosial budaya ndeu paki oi mbaru pada masyarakat Donggo Kabupaten Bima.

Berdasarkan informasi yang digali oleh peneliti dilapangan bahwa upacara ndeu paki oi mbaru masih tetap dilaksanakan oleh sebagian anggota masyarakat donggo, karena menurut beberapa para tokoh adat bahwa warisan adat para leluhur harus tetap dipertahankan. Sebab kalau bukan kita yang akan melestarikan nilai-nilai tradisi maka siapa lagi yang melestarikannya. Nilai sosial budaya semacam ini sudah jarang kita temukan pada masyarakat donggo. Karena sudah dianggap tidak relevan atau ketinggalan dengan perkembangan zaman yang ada. Sikap masyarakat seperti itu yang akan mempercepat nilai budaya luhur masyarakat donggo akan tergerus bahkan akan hilang dari generasi ke generasi.

Makna yang terkandung pada upacara ndeu paki oi mbaru adalah membersihkan jiwa dan raga calon pengantin sebelum akad nikah dilaksanakan. Dengan harapan selama proses pernikahan berlangsung tidak ada halangann yang mengganggu prosesi pernikahan. Berdasarkan informasi dari para informan bahwa ketika seseorang yang akan melangsungkan dan tidak melaksanakan ritual ndeu paki oi mbaru, maka calon pengantin akan mendapatkan hal-hal yang akan mengganngu proses pernikahan.

Selain itu ada makna lain dari upacara ndeu paki oi mbaru bagi masyarakat donggo yakni membersihkan atau menghilangkan kebiasaan-kebiasaan buruk di waktu muda, karena terkadang diwaktu mudanya cenderung melakukan hal-hal yang menyimpang atau melanggar nilai dan norma yang ada. Sehingga setelah menikah tidak boleh lagi melakukan hal demikian. Ada kata penegeasan dalam upacara tersebut yaitu paki (membuang). Dalam artian membuang jauh-jauh kebiasaan yang buruk dan melakukan hal yang baik atau bermanfaat. Dalam tradisi tersebut ada anggapan masyarakat bahwa ketika calon pengantin tidak melakukan ritual ini akan berdampak buruk dalam mengarungi kehidupannya. Bahkan ada perselisihan dalam rumah tangga yang berakhir pada keretakan dalam rumah tangga. Sehingga bagi sebagian masyarakat donggo yang paham akan ritual ini, sangat khawatir kalau menikahkan anak-anaknya tidak mengadakan upacara ndeu paki oi mbaru.

Pada masyarakat Donggo, peneliti temukan bahwa nilai sosial budaya ndeu paki oi mbaru sudah mengalami pergeseran nilai, hal ini karena kebanyakan masyarakat donggo yang peneliti temui, sudah tidak mengetahui apa itu ritual ndeu paki oi mbaru. Terlebih lagi pada kalangan generasi muda yang sudah banyak dipengaruhi oleh arus modern. Sehingga istilah-istilah tradisi sangat asing bagi mereka. Bahkan mereka katakan itu sudah tidak sesuai dengan perkembangan zaman.

2. Faktor yang menyebabkan keberadaan upacara ndeu paki oi mbaru sudah diabaikan bahkan ditinggalkan oleh masyarakat donggo diantaranya yaitu, faktor internal masyarakat sendiri yang tidak terlalu mementingkan tradisi dan budaya secara turun temurun serta menganggap ketika melakukan kegiatan adat cuman membuang biaya dan menghabiskan waktu. Sedangkan faktor eksternal yaitu adanya pengaruh akulturasi budaya dan modernisasi serta pengaruh globalisasi. Sehingga modifikasi tersebut terjadi karena sebab-sebab intern maupun eksteren immaterial, (elly M. Setiadi \& Usman Kolip 2011:610). Dengan adanya kontak dengan budaya lain maka kebudayaan asal akan mengalami pergeseran nilai atau makna. Kalau mengacu pada teori kontak budaya Malinowski, 1983. Bahwa bahwa budaya yang lebih tinggi dan aktif cenderung akan mempengaruhi budaya yang lebih rendah dan pasif melalui kontak, (Dalam Saca,ali 2013). Semakin kuatnya perkembangan 
zaman yang berdampak pada masuknya budaya asing ke Indonesia. Sehingga pesta pernikahan dari budaya luar atau dengan gaya modern mulai diterima tengah masyarakat Indonesia. Sehingga budaya atau tradisi lokal masyarakatnya secara perlahan-lahan ditinggalkan dan bahkan sudah tidak diwariskan dari generasi ke generasi.

\section{A. Kesimpulan}

Berdasarkan uraian hasil dan pembahasan di atas maka yang menjadi kesimpulan dalam penelitian ini adalah sebagai berikut;

1. Tradisi upacara ndeu paki oi mbaru mengandung makna bahwa rnemandikan calon pengantin dengan niat untuk membersihkan diri supaya bersih /suci lahir dan batin. Adapun tujuan dilaksnakanya ndeu paki oi mbaru adalah untuk memohon keberkahan kepada Allah SWT, sehingga calon pengantin yang akan melangsungkan pernikahan akan terlepas dari godaan atau hal-hal buruk. Berdasrkan temuan peneliti di lapangan bahwa, tradisi ndeu paki oi mbaru sudah sangat jarng dilaksanakan oleh masyarakat donggo kabupaten bima.

2. Terdapat perbedaan pandangan terhadap tradisi ndeu paki oi mbaru, ada yang mengatakan bahwa tradisi tersebut perlu dilestarikan karena menjadi warisan budaya dari para leluhur. Sedangkan yang lainnya berpendapat bahwa tradisi ndeu paki oi mbaru sudah tidak relevan dengan zaman sekarang, sehingga tidak perlu dilaksanakan. Pada kondisi seperti ini tradisi ndeu paki oi mbaru mengalami pergeseran nilai.

3. Faktor penyebab eksistensi ndeu paki oi mbaru mulai hilang adalah faktor internal dan faktor eksternal.

\section{B. Saran}

Adapun saran dalam penelitian ini adalah sebagai berikut:

1. Pemerintah setempat dan semua tokohtokoh adat harus melakukan pertemuan secara intens untuk membahas terkait dengan pelestarian nilai-nilai budaya local masyarakat donggo. Sehingga tradisi ndeu paki oi mbaru tidak hilang begitu saja di masyarakat.

2. Diharapkan kepada masyarakat donggo untuk tetap mempelajari atau menggali nilai-nilai kearifan lokal yang dimiliki dan terus diwariskan dari generasi ke generasi.

\section{DAFTAR PUSTAKA}

Basrowi. 2005. Pengantar Sosiologi. Bogor: Ghalia Indonesia.

Koentjaraningrat. 2009. Pengantar Ilmu Antropologi. Edisi Revisi. Jakarta: Rineka Cipta.

Kolip \& Setiadi. 2011. Pengantar Sosiologi.

Jakarta: Kencana.

Moleong, Lexy J. 2014. Metodologi Penelitian Kualitatif Edisi Revisi. Bandung: PT Remaja Rodaskarya.

Ritzer \& J.Goodman. 2010. Teori Sosiologi Modern Edisi Keenam. Jakarta: Kencana.

Ritzer George \& J.Goodman Douglas.2010.Teori Sosiologi Modern Edisi Keenam. Jakarta: Kencana.

Soekanto, Soerjono.2006. Sosiologi Suatu

Pengantar. Jakarta: Rajawali Pers.

Sugiyono. 2010. Metode Penelitian Kualitatif dan $R \& D$. Penerbit Alfabeta: Bandung.

Sumarsono. 2007. Tata Upacara Pengantin Adat Jawa. Yogyakarta: Penerbit Narasi.

Sutopo, H.B. 2002. Metodelogi Penelitian Kualitatif. Surakarta: Sebelas Maret University Press.

Sztompka, Piotr. 2011. Sosiologi Perubahan Sosial, Edisi 1. Jakarta: Prenada Media Group.

Tim. 2013. Kamus Besar Bahasa Indonesia. jakarata: balai pustaka.

(Online) Saca,ali. 2013. Teori-Teori kebudayaan. http://alisaca80.blogspot. com/2013 /07/ teori-teori- kebudayaan .html. diakses tanggal 14 oktober 2021. 